TEKNIK, 42 (3), 2021, 299-308

\title{
Optimalisasi Sistem Monitoring Temperatur Logam Cair pada Proses Pengecoran menggunakan Pyrometer Berbasis Internet of Things (IoT)
}

\author{
Muhammad Fathurrohman", Anugrah Erick Eryantono, Robby Debriand Rumbara \\ Balai Besar Logam dan Mesin, Kementerian Perindustrian, \\ Jl. Sangkuriang No. 12, Bandung, Indonesia 40135
}

\begin{abstract}
Abstrak
Perkembangan teknologi berbasis internet yang pesat menyebabkan terjadinya perubahan pada sektor industri yang dikenal dengan Revolusi Industri 4.0. Industri manufaktur pengecoran merupakan salah satu sektor industri yang harus beradaptasi dengan perkembangan industri 4.0 agar dapat bersaing dalam meningkatkan kualitas produk coran. Beberapa parameter yang mempengaruhi kualitas produk coran adalah temperatur saat penuangan (pouring) dan laju penuangan. Penentuan temperatur penuangan harus memperhitungkan faktor kehilangan panas yang disebabkan oleh waktu pemindahan logam cair dan kondisi lingkungan sekitar. Penentuan temperatur tuang yang kurang tepat dapat menyebabkan terbentuknya porositas (rongga) pada produk hasil pengecoran. Karena pentingnya penentuan temperatur tersebut, maka pada penelitian ini dibangun sistem monitoring berbasis internet of things (IoT) untuk memantau temperatur logam cair saat proses pengecoran secara real-time. Sistem yang dibangun terdiri atas tiga bagian, yaitu: sensor temperatur, gateway dan server. Perangkat pyrometer digunakan untuk mengukur temperatur logam cair dan mengirimkannya ke gateway. Perangkat gateway kemudian mengirimkan data tersebut ke server. Pengguna dapat mengamati temperatur logam cair secara real-time melalui website. Hasil penelitian menunjukkan bahwa dengan sistem monitoring berbasis IoT ini, dapat diperoleh database pengukuran temperatur logam cair yang optimal. Tingkat keakuratan pengukuran data temperatur tersebut mencapai $99,5 \%$.
\end{abstract}

Kata kunci: Internet of Things; monitoring; logam cair; pyrometer; gateway

\begin{abstract}
[Title: Optimization of Metal Pouring Monitoring System using Pyrometer based on IoT] The rapid development of internet-based technology has led to system changes in the industrial sector, known as the Industrial Revolution 4.0. The casting manufacturing industry is one of the industrial sectors that must accompany technology development. Some parameters that affect the casting product are pouring temperature and pouring rate. Determination of pouring temperature should consider the heat loss factor caused by the molten metal's transfer time and the surrounding environmental conditions. Improper pouring temperature determination can cause unwanted porosity in casting products. In this study, we implemented a real-time monitoring system based on the Internet of Things (IoT) in a casting workshop to monitor the molten metal temperature during the casting process. The temperature of molten metal is measured by the pyrometer device and transmitted to the gateway device. Then, the gateway device sends the data to the server to be stored and processed. Users can observe the temperature in real-time through the website. The results show that this IoT-based monitoring system can obtain an optimal temperature database. The accuracy of the measurement of temperature data reaches $99.5 \%$.
\end{abstract}

Keywords: Internet of Things; monitoring; molten metal; pyrometer; gateway

${ }^{*}$ Penulis Korespondensi.

E-mail: rohmanfathur26@gmail.com

\section{Pendahuluan}

Proses pengecoran logam merupakan proses pendinginan logam dari cairan logam yang dimasukkan pada suatu cetakan tertentu hingga menjadi produk logam padatan yang sesuai dengan bentuk cetakannya. Kualitas 


\section{TEKNIK, 42 (3), 2021, 300}

produk hasil proses pengecoran dipengaruhi oleh beberapa parameter, diantaranya adalah temperatur saat penuangan (pouring) dan laju penuangan logam cair. Penentuan temperatur tuang yang kurang tepat dapat menyebabkan terjadinya cacat rongga (porositas) pada produk. Penentuan temperatur tuang ini harus memperhitungkan laju kehilangan panas saat rentang waktu pemindahan cairan logam dari tungku ke cetakan (Kassie, 2013).

Sistem pemantauan temperatur tuang pada proses pengecoran logam menjadi hal yang penting untuk mengontrol kualitas hasil produk coran di industri pengecoran. Pada dasarnya terdapat dua jenis sensor temperatur, yaitu: sensor kontak dan tidak kontak (nonkontak). Sensor temperatur yang umum digunakan untuk mengukur temperatur logam cair pada proses pengecoran adalah termokopel yang termasuk dalam kategori sensor kontak. Proses pengukuran dilakukan dengan cara merendam ujung bagian sensor ke logam cair ke dalam furnace sampai pembacaan temperatur yang ditunjukkan stabil. Metode pengukuran menggunakan termokopel ini memiliki beberapa kelemahan, antara lain: terdapat jeda waktu pengukuran sampai pembacaan stabil. Ujung termokopel hanya bisa dipakai beberapa kali, sehingga tidak bisa dilakukan secara terus-menerus (continue) dan menimbulkan biaya operasional tambahan. Selain itu, metode pengukuran ini cukup berbahaya karena memerlukan operator yang melakukan pengukuran cukup dekat dengan logam cair bersuhu di atas $1000^{\circ} \mathrm{C}$ (Usamentiaga et al., 2012).

Jika dibandingkan dengan sensor temperatur tipe kontak, sensor temperatur tipe non-kontak memiliki beberapa keunggulan, yaitu: dapat mengukur secara akurat temperatur objek tanpa adanya kontak fisik, dapat memantau temperatur objek yang sulit diakses atau objek bergerak, serta rentang pengukuran temperatur yang lebih tinggi. Keunggulan yang lain adalah interval waktu pengukuran yang rapat dan continue, sehingga sesuai untuk kebutuhan monitoring temperatur dengan rentang waktu tertentu (Boughton, 2013).

Pyrometer merupakan jenis sensor temperatur non-kontak yang dapat memenuhi kriteria yang dibutuhkan untuk monitoring temperatur objek pada suhu yang tinggi. Berkaitan dengan kebutuhan monitoring temperatur logam cair pada proses pengecoran, jenis pyrometer yang cocok adalah tipe two-color. Hal ini karena pyr ometer tipe two-color memiliki keunggulan dalam mengukur temperatur absolut permukaan tanpa diperlukan data emisivitas dari permukaan objek tersebut, serta dapat mengkompensasi kondisi lingkungan berdebu yang dapat memengaruhi akurasi hasil pengukuran (Müller \& Renz, 2001; Tapetado et al., 2016).

Pengembangan Internet of Things (IoT) pada berbagai bidang juga menyebabkan terjadinya perubahan sistem pada sektor industri yang ditandai dengan digitalisasi sistem produksi dan proses industri yang kemudian dikenal dengan visi Industri 4.0 atau revolusi industri keempat. Digitalisasi proses produksi ketika diterapkan dapat memiliki dampak positif untuk menghasilkan produk yang berkualitas (Resende et al., 2018).

Proses monitoring merupakan bagian dari sistem yang melakukan penilaian sistematis terhadap suatu objek. Sistem ini bermanfaat dalam pemantauan kondisi suatu objek secara tepat waktu atau real-time (Mudjahidin \& Putra, 2012). Sistem monitoring berbasis IoT secara umum menggunakan sistem akuisisi dan transmisi data khusus yang kemudian disimpan dalam cloud server. Pemanfaatan IoT dalam interaksi dan sensor memungkinkan komunikasi setiap peralatan elektronik ataupun data yang terbaca oleh peralatan tersebut ditampilkan dan disimpan di suatu sistem display dan storage tertentu. Sistem tersebut juga dapat memberikan feedback terhadap peralatan elektronik atau sensor pengirim data awal ataupun kepada peralatan elektronik lainnya (Patel \& Patel, 2016).

Implementasi IoT untuk sistem monitoring temperatur dibangun berdasarkan referensi arsitektur yang terdiri dari 3 perspektif, yaitu: aspek semantic untuk interpretasi data dan informasi, aspek internet yang berhubungan dengan gateway, manajemen data (server), dan networking, serta aspek things yang berfokus pada device seperti sensor dan aktuator (Weyrich \& Ebert, 2016).

Penelitian terkait pengaplikasian IoT pada sektor industri pengecoran logam telah dilakukan oleh Thillai Rani \& Sivakumar. Sistem monitoring berbasis IoT digunakan untuk menganalisis tingkat konsumsi energi pada workshop pengecoran logam. Hasil penelitian menunjukkan bahwa dengan memanfaatkan teknologi IoT, kontrol tingkat konsumsi energi dan pengambilan keputusan terkait manajemen energi di industri pengecoran logam dapat dilakukan dengan mudah. Sehingga, ongkos produksi dapat dikurangi secara signifikan (Rani \& Sivakumar, 2021).

Sanjith et al. telah melakukan penelitian terkait pemanfaatan teknologi IoT untuk monitoring temperatur logam cair pada proses pengelasan. Monitoring dilakukan untuk mengontrol kenaikan temperatur logam cair tersebut. Kenaikan temperatur yang terlalu tinggi dapat menyebabkan perubahan struktur mikro. Sistem yang dibangun terdiri dari sensor temperatur LM-35, transmiter wireless, mikrokontroler, serta server. Data hasil pengukuran temperatur kemudian dievaluasi menggunakan metode taguchi untuk menentukan temperatur optimal yang terjadi pada zona pengelasan (Sanjith et al., 2021). Perangkat yang digunakan pada sistem monitoring berbasis IoT pada penelitian tersebut 


\section{TEKNIK, 42 (3), 2021, 301}

masih sebatas skala lab, sehingga belum cukup kuat (robust) jika diaplikasikan pada skala industri.

Sampai saat ini, penggunaan teknologi IoT pada sistem monitoring temperatur logam cair di workshop pengecoran masih belum banyak diaplikasikan. Oleh karena itu, pada penelitian ini sistem monitoring pengukuran temperatur logam cair berbasis IoT dibangun pada workshop pengecoran. Sistem monitoring dirancang berdasarkan pada referensi arsitektur yang terdiri dari sensor temperatur, gateway Industrial Internet of Things (IIoT), dan perangkat server. Penentuan jenis dan spesifikasi perangkat-perangkat tersebut disesuaikan dengan kebutuhan industri. Hasil pengukuran temperatur tersebut dimanfaatkan sebagai data analisis untuk menentukan temperatur proses pengecoran yang sesuai. Pengukuran temperatur menggunakan sensor tipe kontak yang selama ini dilakukan hanya sebatas pengukuran temperatur untuk memutuskan logam cair siap dituangkan ke dalam cetakan. Pemantauan dan pengumpulan data secara realtime tidak bisa dilakukan menggunakan sensor temperatur tipe kontak. Oleh karena itu, pada sistem monitoring berbasis IoT yang dibangun, sensor yang digunakan adalah sensor temperatur tipe non-kontak, yaitu pyrometer.

Justifikasi hasil pengukuran temperatur logam cair pada sistem monitoring berbasis IoT diperlukan untuk mengetahui kualitas data hasil pengukuran berdasarkan tingkat akurasi dan presisi sesuai dengan batas toleransi yang diizinkan. Tingkat akurasi dan presisi dapat diketahui dengan cara membandingkan data hasil pengukuran temperatur yang diperoleh dari sistem monitoring berbasis IoT dengan pengukuran secara langsung menggunakan sensor temperatur kontak atau termokopel. Tingkat akurasi dan presisi ditentukan dengan analisis pengolahan data statistik, yaitu: bias dan variance. Bias menggambarkan perbedaan antara ratarata hasil pengukuran dengan nilai target. Sedangkan variance menunjukkan tingkat persebaran data hasil

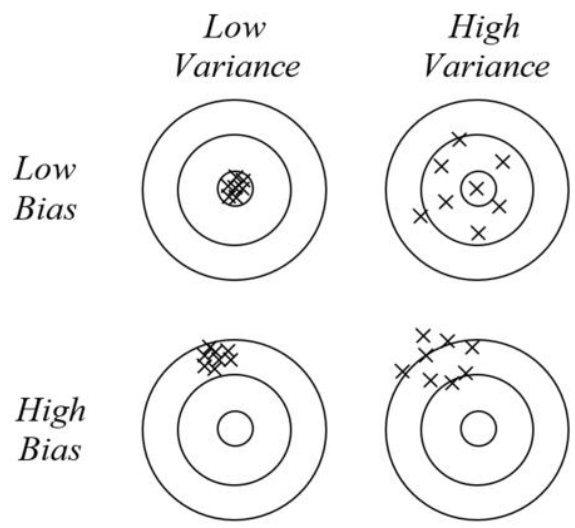

Gambar 1. Ilustrasi bias dan variance pengukuran pada sistem monitoring (Khandelwal, 2018). Nilai bias dan variance pada suatu model pengukuran diilustrasikan pada Gambar 1 (Domingos, 2012).

Pada Gambar 1 ditunjukkan bahwa kualitas data yang baik akan menghasilkan bias dan variance yang rendah. Sedangkan bias dan variance yang tinggi memperlihatkan hasil pengukuran pada sistem monitoring yang belum mumpuni. Salah satu cara untuk meningkatkan kualitas hasil pengukuran tersebut adalah dengan melakukan kalibrasi alat.

Penelitian ini bertujuan untuk mengoptimalkan sistem monitoring temperatur logam cair pada saat proses pengecoran logam menggunakan pyrometer berbasis IoT agar memiliki tingkat keakuratan yang tinggi.

\section{Bahan dan Metode}

Sistem monitoring temperatur yang akan dikembangkan terdiri atas 3 komponen utama, yaitu: Sensor temperatur, Gateway Industrial Internet of Things (IIoT), dan Server. Pemilihan komponenkomponen utama dalam pengembangan sistem monitoring temperatur logam cair pada proses pengecoran ini didasarkan pada kebutuhan saat proses pengecoran dan ketersediaan teknologi digital yang telah teruji di dunia industri.

\subsection{Sensor Temperatur}

Proses pengecoran logam di dunia industri biasa dilakukan di ruangan terbuka sehingga toleransi hasil pengukuran logam cair saat proses pengecoran ditetapkan pada angka $20-30^{\circ} \mathrm{C}$ (temperatur ruang ratarata di Kota Bandung). Kondisi lingkungan yang berdebu dan berasap menjadi tantangan tersendiri dalam proses pengukuran temperatur logam cair tersebut. Oleh karena itu, harus digunakan sensor temperatur jenis nonkontak yaitu pyrometer yang memiliki tingkat kepresisian pengukuran yang tinggi, dapat mengeliminasi kondisi lingkungan yang berasap dan berdebu, dan data hasil pengukurannya dapat disimpan dalam sistem database khusus agar dapat dievaluasi.

Pyrometer merupakan perangkat instrumen sensor temperatur yang dapat menangkap radiasi panas dari sumber (Jack et al., 2016). Pada penelitian ini, pyrometer yang dipilih adalah tipe two-color. Temperatur yang ditangkap oleh pyrometer berupa sinyal radiasi spektrum. Pada pyrometer tipe two-color, fenomena tersebut dijelaskan pada persamaan (1).

$$
T_{R}=\left(\frac{1}{T}+\frac{\ln \left(\varepsilon_{1} / \varepsilon_{2}\right)}{C_{2} \cdot\left(\lambda_{2}{ }^{-1}-\lambda_{1}{ }^{-1}\right)}\right)
$$

$\mathrm{T}_{\mathrm{R}}$ atau temperatur rasio merupakan temperatur yang terukur oleh two-color pyrometer. Sedangkan $\mathrm{T}$ adalah temperatur sesungguhnya dari objek yang diukur. 


\section{TEKNIK, 42 (3), 2021, 302}

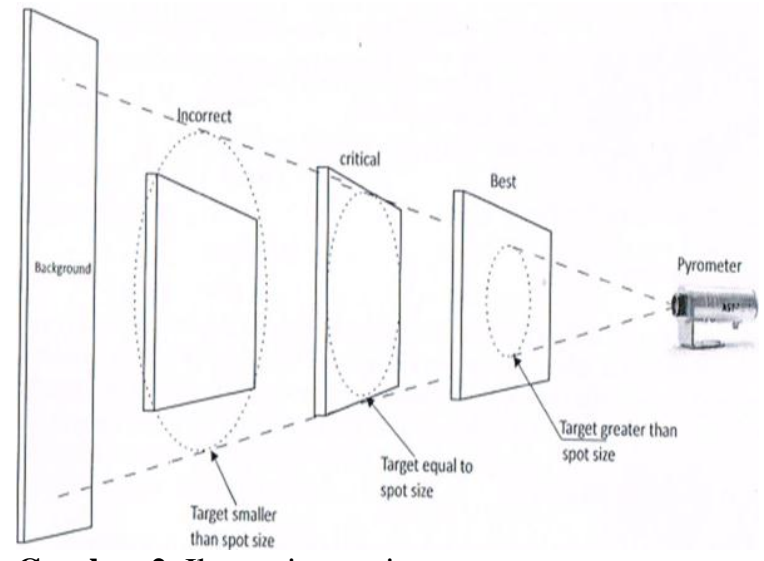

Gambar 2. Ilustrasi spot size pyrometer

Dari persamaan (1) terlihat bahwa untuk objek ukur yang emisivitasnya terbaca sama oleh kedua sensor $\left(\varepsilon_{1}=\varepsilon_{2}\right)$ atau biasa disebut gray body maka bagian kedua dari bagian sebelah kanan di persamaan tersebut bernilai nol sehingga $\mathrm{T}_{\mathrm{R}}$ sama dengan $\mathrm{T}$ (Müller \& Renz, 2001).

Faktor geometri merupakan salah satu faktor penting yang dapat mempengaruhi nilai koefisien pengukuran temperatur pyrometer $(\mathrm{K})$. Pada dasarnya semakin dekat jarak pyrometer terhadap objek, semakin kecil daerah ukur dari permukaan objek (spot size) sehingga semakin presisi hasil pengukurannya. Ilustrasi spot size ditampilkan pada Gambar 2.

Posisi terbaik adalah posisi dimana spot size pyrometer lebih kecil dari ukuran objek (ilustrasi pada gambar paling kanan). Spot size juga dipengaruhi oleh sudut ukur pyrometer. Semakin landai sudut ukurnya, maka semakin besar spot size sehingga semakin berkurang tingkat presisi hasil pengukuran.

Berdasarkan hasil telaah dan pertimbangan yang telah dijelaskan sebelumnya, maka pada kegiatan penelitian ini digunakan pyrometer dengan spesifikasi yang dijelaskan pada Tabel 1. Pyrometer ini diaplikasikan pada pengukuran temperatur logam cair, khususnya logam ferro dengan ketentuan jarak pyrometer ke permukaan logam cair kurang lebih $1 \mathrm{~m}$ horizontal ke samping dan $1 \mathrm{~m}$ vertikal ke atas dengan sudut ukur $30-45^{\circ}$. Jarak tersebut merupakan jarak aman bagi operator untuk mengukur temperatur dan untuk menjaga temperatur di dalam pyrometer. Dengan jarak ukur pyrometer dan objek sekitar 1-1,5 m artinya daerah ukur (spot size) adalah sebesar 3-5 mm. Nilai ini sudah memenuhi kriteria pengukuran karena lebih kecil dari area/ ukuran objek yang diukur, yaitu logam cair.

Pada penelitian kali ini, digunakan alat ukur temperatur pembanding yang biasa digunakan di industri pengecoran, yaitu termokopel tipe R. Sensor termokopel tipe $\mathrm{R}$ merupakan sensor temperatur jenis kontak yang memiliki akurasi, ketahanan panas $\left( \pm 1600{ }^{\circ} \mathrm{C}\right)$, serta
Tabel 1. Spesifikasi pyrometer

\begin{tabular}{ll}
\hline \multicolumn{1}{c}{ Kriteria } & \multicolumn{1}{c}{ Spesifikasi } \\
\hline Tipe & Two-color \\
Jangkauan ukur & $800-2500^{\circ} \mathrm{C}$ \\
Perbandingan jarak ke spot size & $300: 1$ \\
Rasio Emisivitas & $0,7-1,25$ \\
Akurasi & $\pm 0,5 \%$ tiap $1^{\circ} \mathrm{C}$ \\
Analog output & $4-20 \mathrm{~mA}$ \\
Digital output & $\mathrm{RS}-485$ \\
Daya & Max 2,5 Watt \\
Berat & 1200 gram \\
Ukuran & $\varnothing 56 \times 185,5 \mathrm{~mm}$ \\
Pengarah & Laser \\
\hline
\end{tabular}

stabilitas pengukuran yang baik. Untuk menjaga kualitas hasil pengukuran, termokopel tipe $\mathrm{R}$ tersebut dikalibrasi secara berkala.

Penyimpangan hasil pengukuran temperatur menggunakan pyrometer dapat dihitung dengan persamaan (2) dan (3).

$$
\begin{aligned}
& D_{p}=T_{p}-T_{T} \\
& \% D_{p}=\frac{D_{p}}{T_{T}} \times 100 \%
\end{aligned}
$$

Dimana $D_{p}$ adalah deviasi pengukuran pyrometer, $T_{p}$ adalah temperatur hasil pengukuran pyrometer, dan $T_{T}$ adalah temperatur hasil pengukuran termokopel.

Tingkat akurasi dan presisi pada sistem pengukuran menggunakan pyrometer dapat diketahui melalui perhitungan tingkat bias dan variance. Bias diungkapkan dalam bentuk nilai mutlak yang merupakan selisih antara nilai rata-rata temperatur hasil pengukuran pyrometer dengan hasil pengukuran termokopel. Nilai bias yang semakin rendah menunjukkan akurasi pengukuran pyrometer yang semakin baik. Persamaan matematika untuk menentukan tingkat bias ditunjukkan pada persamaan (4) dan (5).

$$
\begin{aligned}
& \text { Bias }=\left|\overline{T_{p}}-T_{T}\right| \\
& \% \text { Bias }=\frac{\left|\overline{T_{p}}-T_{T}\right|}{T_{T}} \times 100 \%
\end{aligned}
$$

Dimana $\overline{T_{p}}$ adalah temperatur rata-rata pengukuran pyrometer dan $T_{T}$ adalah temperatur hasil pengukuran termokopel. Sedangkan variance merupakan ukuran persebaran data temperatur hasil pengukuran pyrometer. Ukuran persebaran data tersebut diungkapkan pada persamaan (6). 


\section{TEKNIK, 42 (3), 2021, 303}

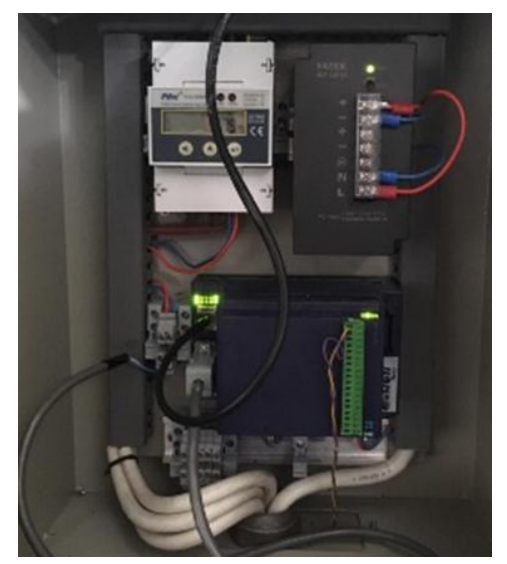

Gambar 3. Gateway IIoT (Bawah) dan Power Supply (Kanan Atas)

$$
S^{2}=\frac{n \sum_{i=1}^{n} T_{p_{i}}^{2}-\left(\sum_{i=1}^{n} T_{p_{1}}\right)^{2}}{n(n-1)}
$$

Dimana $s^{2}$ adalah variance, $T_{p_{i}}$ adalah Nilai $T_{p}$ ke $i$, dan $n$ adalah ukuran sampel.

\subsection{Gateway Industrial Internet of Things (IIoT)}

Perkembangan teknologi komunikasi dan IoT menyebabkan perubahan metode komunikasi pada sistem manajemen data di industri. Komunikasi antar device di lapangan yang awalnya tidak bisa dilakukan secara langsung kini bisa dimungkinkan dengan cara menghubungkannya langsung dengan cloud server. Industrial modular router dan data gateway merupakan sebuah perangkat yang dirancang sebagai sistem integrator dan media komunikasi pada sistem industri. Fleksibilitas perangkat ini dapat mengakomodasi berbagai jenis tipe komunikasi dan protokol yang digunakan untuk berbagai jenis device.

Industrial router dan data gateway berfungsi sebagai media komunikasi antara device di lapangan

Tabel 2. Spesifikasi Gateway IIoT eWon Flexy 202

\begin{tabular}{ll}
\hline \multicolumn{1}{c}{ Perangkat } & \multicolumn{1}{c}{ Spesifikasi } \\
\hline Key features & Flexible WAN \& Field \\
Processor & ARM9 \\
LAN Port & Ethernet port, UTP5, RJ45 \\
Serial Port & RS232, RS422, RS485 \\
Connection & 2 DIs, 1 DO \\
Additional slot & 4 slot fillers \\
Mounting & DIN rail \\
Power & 24 VDC \\
Extension & FLX3401, I/O \\
\hline
\end{tabular}

dengan cloud server maupun pengguna. Prinsip kerjanya, data yang didapatkan oleh device di lapangan akan

dikirimkan ke sistem integrator melalui protokol komunikasi yang disesuaikan dengan protokol yang dimiliki oleh device (misalnya Modbus). Gateway IIoT akan mengolah data tersebut dan mengirimkannya ke server atau cloud melalui protokol komunikasi yang disesuaikan juga (misalnya HTTP), sehingga data dapat terkirim dan terbaca di server (eWon, 2020).

Gateway IIoT yang digunakan pada sistem ini adalah eWon Flexy 202 dengan spesifikasi yang ditunjukkan pada Tabel 2. Gateway IIoT terpasang pada DIN rail di dalam sebuah industrial box. Gateway IIoT terhubung dengan power supply/ adaptor di atasnya. Data temperatur dari pyrometer masuk ke gateway IIoT melalui extension card yang berwarna hijau. Data tersebut dikirim ke server (hardware) melalui LAN port RJ45 menggunakan kabel LAN UTP CAT 6. Rangkaian Gateway IIoT yang telah terpasang ditampilkan pada Gambar 3.

\subsection{Server, Aplikasi Backend dan Frontend}

Perangkat server (hardware) pada sistem monitoring temperatur ini dipersiapkan sebagai media penyimpanan berbasis cloud. Spesifikasi PC server yang digunakan dijelaskan pada Tabel 3.

Perangkat server berjalan menggunakan sistem operasi centOS berbasis Linux yang diinstall menggunakan Virtual Machine. Pada sistem operasi Linux ini, platform perangkat lunak Node.js berjalan pada sisi peladen dan aplikasi jaringan. Selain itu sistem manajemen basis data SQL yaitu MySQL juga digunakan pada sistem operasi Linux ini. Node.js digunakan untuk membangun aplikasi web dan juga API (Application Programming Interface), sedangkan MySQL digunakan sebagai database untuk menyimpan data hasil pengukuran temperatur pada pyrometer.

Sistem arsitektur IoT yang dijalankan pada server terbagi dalam dua bagian, yaitu: bagian backend dan bagian frontend. Bagian frontend dari sebuah website adalah bagian yang dapat dilihat secara langsung oleh pengguna (user inerface), serta berkaitan dengan pengalaman pengguna (user experience) (Prawastiyo \& Hermawan, 2020). Bahasa script yang digunakan untuk pengembangan bagian frontend server sistem monitoring ini berbasis JavaScript.

Backend adalah bagian belakang layar dari sebuah website. Pada bagian ini juga dibangun aplikasi yang menghubungkan antar mesin/ perangkat. Performa aplikasi server menjadi hal yang utama, semakin banyak penanganan request terhadap client dengan konsumsi sumber daya komputer minimal akan dapat menekan biaya operasional.

Terdapat beberapa bahasa pemrograman aplikasi web, yaitu: PHP, node.js dan phyton. Dari ketiga bahasa tersebut, node.js memiliki keunggulan dalam hal melaksanakan perintah tanpa perhitungan kriptografi intensif khususnya dalam hal respon terhadap request

\footnotetext{
doi: $10.14710 /$ knik. v42i3.36351
}

Copyright (C 2021, TEKNIK, p-ISSN: 0852-1697, e-ISSN: 240-9919 


\section{TEKNIK, 42 (3), 2021, 304}

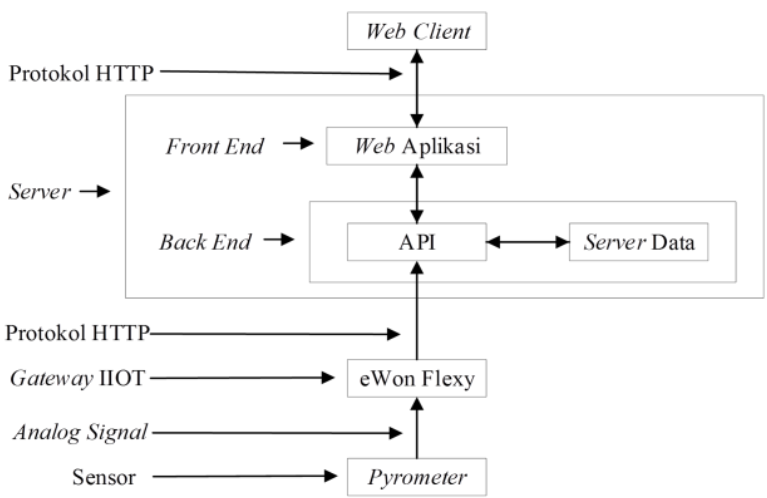

Gambar 5. Topologi Logical

yang masuk serta lebih cepat saat mengakses hardware. Node.js memiliki pustaka server HTTP sendiri sehingga memungkinkan untuk menjalankan server web tanpa menggunakan program server web seperti Apache atau Nginx (Rompis \& Aji, 2018).

Bahasa pemrograman JavaScript pada awalnya digunakan untuk membuat HTML dan CSS dalam web browser yang dijalankan pada bagian frontend. Kemudian pada Tahun 2009 bahasa pemrograman ini digunakan juga untuk membuat aplikasi pada server sehingga disebut juga sebagai Node.js (node JavaScript) (Shah \& Soomro, 2017). Penggunaan bahasa yang sama pada sisi frontend dan backend ini menyebabkan komunikasi antara keduanya menjadi lebih efisien.

Pengembangan aplikasi backend dan frontend pada sistem monitoring temperatur ini dibangun menggunakan perangkat lunak node.js. Gambar 4 berikut menjelaskan topologi logical yang dibangun (Eryantono et al., 2020). Diagram yang ditunjukkan pada Gambar 4 merepresentasikan rancangan dan desain sistem monitoring temperatur di workshop pengecoran. Berdasarkan gambar tersebut dapat dijelaskan bahwa

Tabel 3. Spesifikasi perangkat server

\begin{tabular}{ll}
\hline \multicolumn{1}{c}{ Perangkat } & \multicolumn{1}{c}{ Spesifikasi } \\
\hline PC Server & HPE ProLiant DL20 Gen9; Intel \\
& Xeon E3-1220v6 Quad Core; \\
& ROM 16 GB \\
HDD & Harddisk HPE 1.2 TB SAS 10K \\
RAM & HPE DL20 8GB (1x8GB) Dual \\
& Rank x8 DDR \\
Routerboard & IU rackmount, 12x Gigabit \\
CCR 1036-12G- & Ethernet, 4xSFP cages, LCD 36 \\
4S & cores x 1.2 GHz CPU, 4GB \\
Module & RAM Konverter fiber (optic-RJ45) \\
Tranceiver & untuk Mikrobits SFP \\
Fiber Optic SFP & Transceiver (RJ45) \\
\hline
\end{tabular}

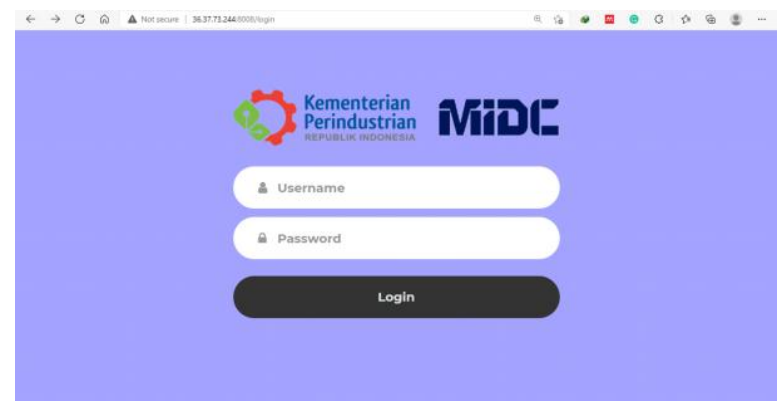

Gambar 4. Tampilan awal aplikasi monitoring BBLM

Web Aplikasi adalah bagian frontend yang berinteraksi langsung dengan Web Client/ User. Sedangkan pada sisi backend terdapat API dan Server Data. Aplikasi berbasis web menggunakan database mysql sebagai backend. Akses ke database tidak dapat dilakukan secara langsung, melainkan melalui perantara Application Programming Interface (API). Fungsi API adalah untuk menjembatani antara web aplikasi dengan server data, artinya setiap data pada server data yang akan ditampilkan pada Web Aplikasi harus diatur oleh API terlebih dahulu. API digunakan sebagai standar komunikasi agar aplikasi dan perangkat yang berbeda dapat berkomunikasi, serta untuk membatasi akses langsung ke server data. API yang digunakan berbasis HTTP.

Data pengukuran temperatur dari pyrometer yang diperoleh berupa sinyal analog 4-20 mA. Data yang berupa sinyal analog dikirimkan ke IIoT Gateway eWon untuk diterjemahkan menjadi data digital. Gateway eWon kemudian mengirimkan data tersebut ke server data dengan interval pengiriman (sample time) 5 detik menggunakan protokol HTTP.

\section{Hasil dan Pembahasan}

Sistem monitoring temperatur logam cair pada proses pengecoran di BBLM dengan konfigurasi peralatan utama, yaitu: pyrometer two-color, gateway IIoT dan server beserta aplikasinya ini telah berhasil mendapatkan database temperatur penuangan logam yang bermanfaat untuk penelitian di bidang pengecoran logam. Selain itu, konfigurasi sistem monitoring ini juga dapat diterapkan pada berbagai sektor industri, khususnya industri pengecoran logam.

Pengambilan sampel data temperatur hasil pengukuran menggunakan pyrometer pada sistem monitoring temperatur dilakukan sebanyak tiga kali ketika proses pengecoran sedang dilaksanakan di workshop pengecoran BBLM. Data hasil pengukuran dapat diakses melalui web server BBLM. Tampilan awal web server ditunjukkan pada Gambar 5. 


\section{TEKNIK, 42 (3), 2021, 305}

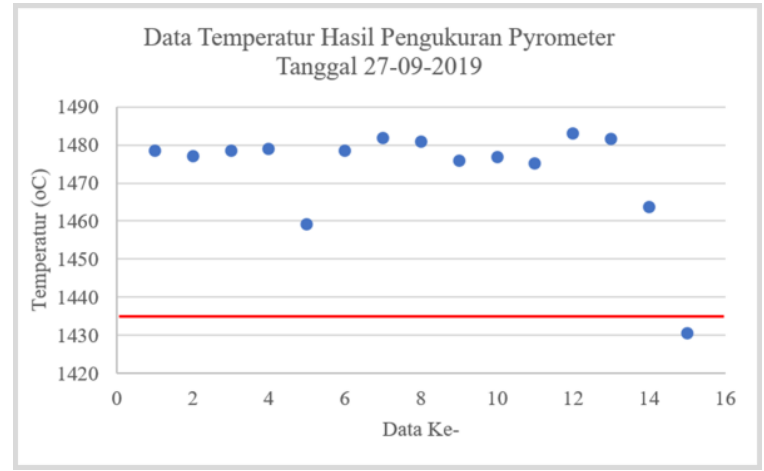

Gambar 7. Sebaran data temperatur pada proses pengecoran pertama

Pengambilan sampel data pertama dilakukan pada tanggal 27 September 2019. Data monitoring temperatur yang telah tersimpan di server kemudian diolah untuk diamati sebaran data dan deviasinya. Sebaran data dan deviasi pengukuran ditampilkan pada Gambar 6 dan Tabel 4.

Hasil pengukuran temperatur logam cair menggunakan termokopel $\left(\mathrm{T}_{\mathrm{T}}\right)$ sebagai temperatur pembanding ditunjukkan oleh garis merah pada Gambar 7, yaitu: $1435^{\circ} \mathrm{C}$. Sedangkan titik-titik warna biru adalah hasil pengukuran menggunakan pyrometer yang datanya dikirim ke server setiap lima detik sekali. Dari 15 data sampel pengukuran temperatur yang dilakukan selama kurang lebih 1 menit 15 detik tersebut, terdapat 1 data yang nilainya mendekati temperatur target, yaitu data ke15 yang bernilai $1430^{\circ} \mathrm{C}$ (lihat Tabel 4). Sedangkan mayoritas sebaran data pengukuran temperatur menunjukkan deviasi pengukuran di atas $40^{\circ} \mathrm{C}$. Hasil perhitungan menunjukkan nilai bias sebesar 3\%, sedangkan variance sebesar 184,3.

Hasil perhitungan tersebut menunjukkan tingkat

Tabel 5. Sebaran data temperatur dan deviasinya pada proses pengecoran pertama

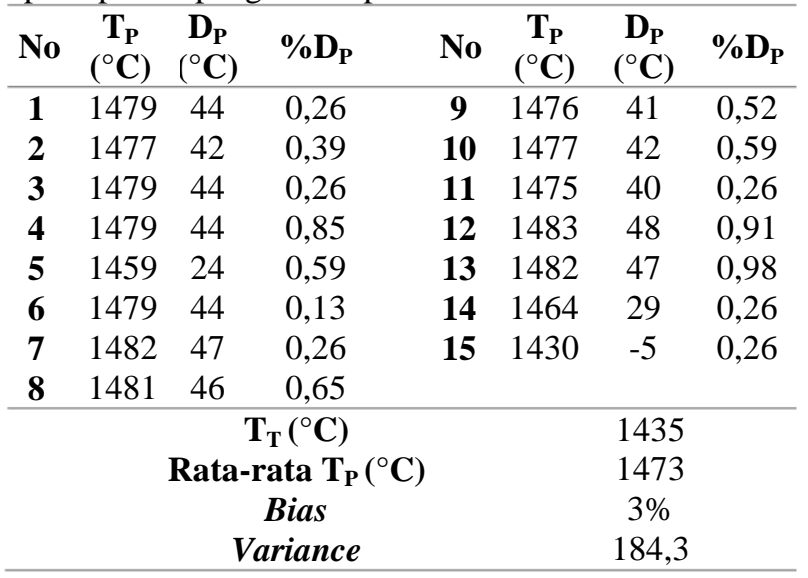

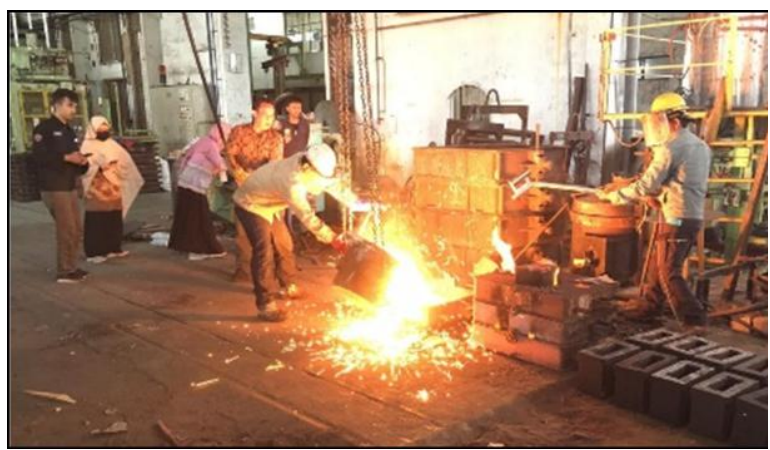

Gambar 6. Proses Pengukuran Temperatur Tuang Logam cair

bias dan variance yang cukup besar, sehingga akurasi dan presisi pada sistem monitoring belum cukup baik. Hal itu sesuai dengan teori yang menyatakan bahwa semakin besar nilai bias dan variance, maka semakin rendah akurasi dan presisi hasil pengukuran (Khandelwal, 2018). Penyimpangan yang terjadi pada pengukuran ini disebabkan oleh penentuan rasio emisivitas pyrometer yang kurang tepat ataupun pengaturan parameter pada gateway IIoT eWon Flexy yang belum sesuai. Untuk meminimalkan tingkat bias dan variance tersebut, perlu dilakukan kalibrasi pada pyrometer dengan cara menyesuaikan kembali rasio emisivitas pyrometer.

Pengambilan sampel data kedua dilakukan tanggal

Tabel 4. Hasil pengukuran temperatur pada proses pengecoran kedua

\begin{tabular}{llll}
\hline No. & $\mathbf{T}_{\mathbf{P}}\left({ }^{\circ} \mathbf{C}\right)$ & No. & $\mathbf{T}_{\mathbf{P}}\left({ }^{\circ} \mathbf{C}\right)$ \\
\hline 1 & 1520 & 17 & 1525 \\
2 & 1518 & 18 & 1516 \\
3 & 1520 & 19 & 1515 \\
4 & 1511 & 20 & 1520 \\
5 & 1515 & 21 & 1510 \\
6 & 1526 & 22 & 1509 \\
7 & 1528 & 23 & 1520 \\
8 & 1514 & 24 & 1520 \\
9 & 1532 & 25 & 1522 \\
$10 \quad 1505$ & 26 & 1546 \\
$\mathbf{1 1} \quad \mathbf{8 0 0}$ & 27 & 1539 \\
$\mathbf{1 2} \quad \mathbf{8 0 0}$ & 28 & 1554 \\
$\mathbf{1 3} \quad \mathbf{8 0 0}$ & $\mathbf{2 9}$ & $\mathbf{8 0 0}$ \\
$\mathbf{1 4} \quad \mathbf{8 0 0}$ & $\mathbf{3 0}$ & $\mathbf{8 0 0}$ \\
15 & 1536 & 31 & 1517 \\
$\mathbf{1 6} \quad \mathbf{8 0 0}$ & & \\
\hline $\mathbf{T}_{\mathbf{T}}\left({ }^{\circ} \mathbf{C}\right)$ & & 1524 \\
Rata-rata & $\mathbf{T}_{\mathbf{P}}\left({ }^{\circ} \mathbf{C}\right)$ & & 1359 \\
Bias & & $11 \%$ \\
Variance & & 94383,61 \\
\hline
\end{tabular}




\section{TEKNIK, 42 (3), 2021, 306}

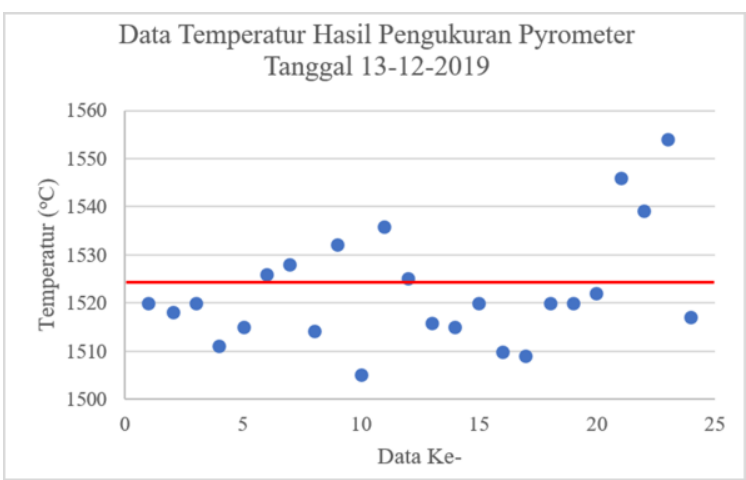

Gambar 9. Sebaran data temperatur pada proses pengecoran kedua

13 Desember 2019. Waktu pengambilan data diperpanjang menjadi 2 menit dan interval pengiriman data diperpendek menjadi 4 detik. Data hasil pengukuran tersebut ditampilkan pada Tabel 5. Pada Tabel 5 diperlihatkan hasil tingkat bias dan variance yang tinggi, yaitu: $11 \%$ bias dan variance sebesar 94383,61 . Hal itu dikarenakan terdapat 7 data $(22,6 \%)$ yang memiliki nilai pengukuran $800^{\circ} \mathrm{C}$ yang merupakan batas minimum pengukuran pyrometer $\left(800-2500^{\circ} \mathrm{C}\right)$. Hal ini terjadi karena spot size pyrometer tidak mengenai area logam cair dikarenakan posisi pyrometer yang tidak stabil. Ketidakstabilan ini terjadi akibat tenaga operator yang memegang pyrometer sudah berkurang mengingat berat total pyrometer beserta dudukannya mencapai $3 \mathrm{~kg}$.

Kesalahan pengukuran tersebut merupakan kesalahan acak yang menyebabkan variance bernilai

Tabel 6. Sebaran data temperatur dan deviasinya pada proses pengecoran kedua

\begin{tabular}{|c|c|c|c|c|c|c|c|}
\hline No & $\begin{array}{c}\mathbf{T}_{\mathbf{P}} \\
\left({ }^{\circ} \mathbf{C}\right)\end{array}$ & $\begin{array}{c}\mathbf{D}_{\mathbf{P}} \\
\left({ }^{\circ} \mathbf{C}\right)\end{array}$ & $\% \mathrm{D}_{\mathrm{P}}$ & No & $\begin{array}{c}\mathbf{T}_{\mathbf{P}} \\
\left({ }^{\circ} \mathbf{C}\right)\end{array}$ & $\begin{array}{c}\mathbf{D}_{\mathbf{P}} \\
\left({ }^{\circ} \mathbf{C}\right)\end{array}$ & $\% \mathrm{D}_{\mathrm{P}}$ \\
\hline 1 & 1520 & -4 & 0,26 & 13 & 1516 & -8 & 0,52 \\
\hline 2 & 1518 & -6 & 0,39 & 14 & 1515 & -9 & 0,59 \\
\hline 3 & 1520 & -4 & 0,26 & 15 & 1520 & -4 & 0,26 \\
\hline 4 & 1511 & -13 & 0,85 & 16 & 1510 & -14 & 0,91 \\
\hline 5 & 1515 & -9 & 0,59 & 17 & 1509 & -15 & 0,98 \\
\hline 6 & 1526 & 2 & 0,13 & 18 & 1520 & -4 & 0,26 \\
\hline 7 & 1528 & 4 & 0,26 & 19 & 1520 & -4 & 0,26 \\
\hline 8 & 1514 & -10 & 0,65 & 20 & 1522 & -2 & 0,13 \\
\hline 9 & 1532 & 8 & 0,52 & 21 & 1546 & 22 & 1,44 \\
\hline 10 & 1505 & -19 & 1,24 & 22 & 1539 & 15 & 0,98 \\
\hline 11 & 1536 & 12 & 0,78 & 23 & 1554 & 30 & 1,96 \\
\hline 12 & 1525 & 1 & 0,06 & 24 & 1517 & -7 & 0,45 \\
\hline \multicolumn{4}{|c|}{$\mathbf{T}_{\mathrm{T}}\left({ }^{\circ} \mathbf{C}\right)$} & & \multicolumn{3}{|c|}{1524} \\
\hline & \multicolumn{3}{|c|}{ Rata-rata $\mathbf{T}_{\mathbf{P}}\left({ }^{\circ} \mathbf{C}\right)$} & & \multicolumn{3}{|c|}{1522} \\
\hline & \multicolumn{3}{|c|}{ Bias } & & \multicolumn{3}{|c|}{$0,1 \%$} \\
\hline & \multicolumn{3}{|c|}{ Variance } & & \multicolumn{3}{|c|}{140,2} \\
\hline
\end{tabular}

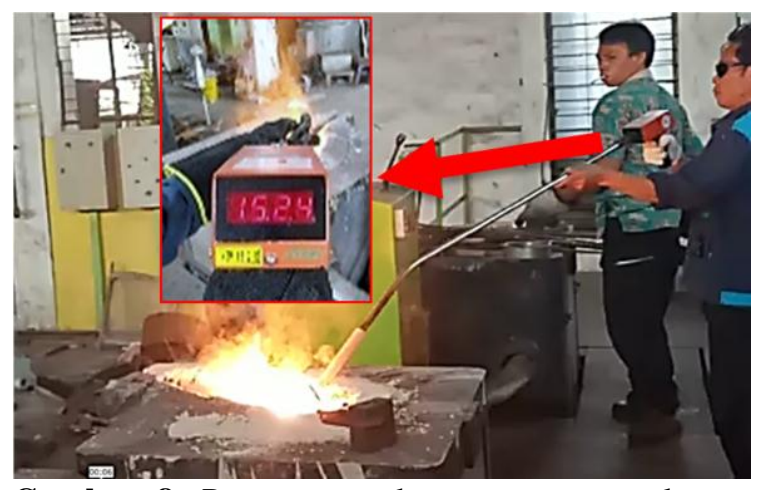

Gambar 8. Proses pengukuran temperatur logam cair mengunakan termokopel

besar. Cukup sulit untuk menghilangkan kesalahan tersebut karena keterbatasan sistem yang sudah dibangun. Hal itu sebagaimana ditunjukkan pada proses pengukuran temperatur logam cair menggunakan pyrometer yang diperlihatkan pada Gambar 7.

Jika error pengukuran akibat faktor manusia tersebut diabaikan, maka sebaran data temperatur menjadi seperti yang ditampilkan pada Gambar 8. Garis merah pada Gambar 8 merupakan besaran temperatur hasil pengukuran dengan termokopel. Proses pengukuran temperatur logam cair menggunakan termokopel dapat dilihat pada Gambar 9. Pada pengambilan data sampel kedua ini nilai temperatur yang terukur menggunakan termokopel adalah $1524^{\circ} \mathrm{C}$ (Gambar 9, diperbesar).

Jika sebaran data temperatur yang diperlihatkan pada Gambar 8 dihitung masing-masing deviasi pengukurannya, maka besaran nilai deviasi tersebut

Tabel 7. Sebaran data temperatur dan deviasinya pada proses pengecoran ketiga

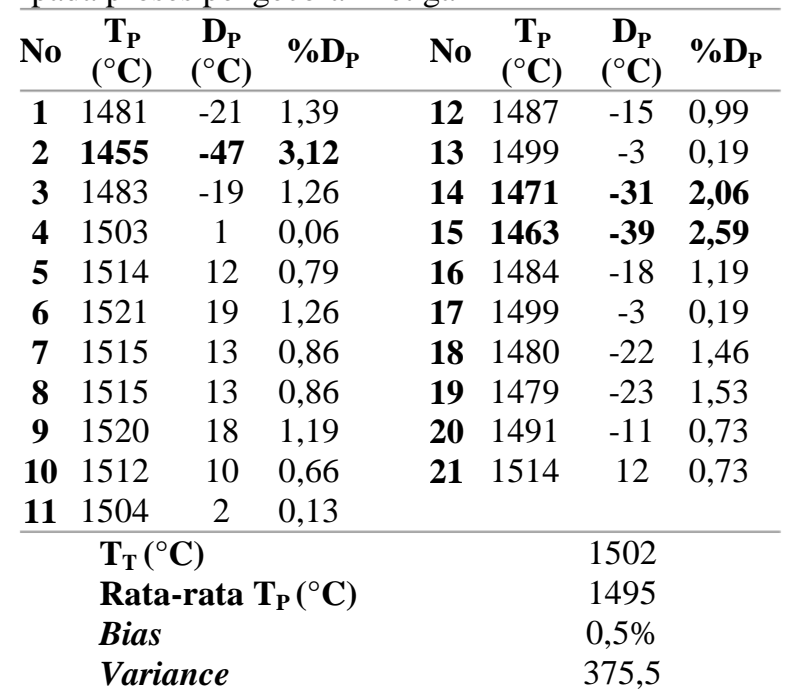




\section{TEKNIK, 42 (3), 2021, 307}

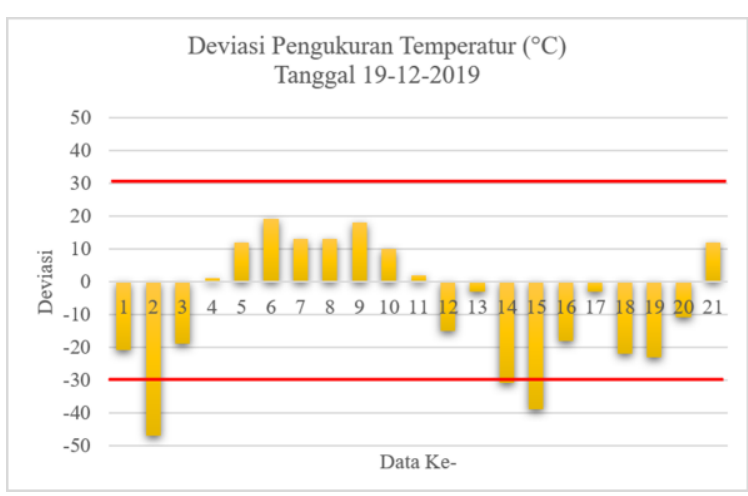

Gambar 10. Deviasi pengukuran pyrometer pada proses pengecoran ketiga

menjadi sebagaimana yang ditunjukkan pada Tabel 6 . Dari Tabel 6 tersebut dapat diamati bahwa deviasi pengukuran terbesar adalah $30^{\circ} \mathrm{C}$ atau $1,96 \%$ kesalahan. Tingkat bias dan variance pada data pengambilan sampel kedua ini menunjukkan hasil yang lebih rendah jiga dibandingkan pada data pengambilan sampel kedua, yaitu: $0,1 \%$ bias dan variance sebesar 140,2. Hal tersebut menunjukkan bahwa penentuan rasio emisivitas dan pengaturan parameter pada gateway IIoT eWon Flexy sudah tepat.

Sampel data pengukuran temperatur yang ketiga dilakukan pada proses pengecoran tanggal 19 Desember 2019. Data sampel diambil selama 1 menit untuk mengurangi kesalahan pengukuran akibat kelelahan operator seperti pada pengambilan sampel data kedua dengan interval pengiriman data yang diperpendek menjadi 3 detik. Sebaran data dan deviasi temperatur hasil pengukuran pyrometer ditampilkan pada Gambar 10 dan Tabel 7. Hasil pengukuran temperatur menggunakan termokopel didapat sebesar $1502^{\circ} \mathrm{C}$.

Sebaran data dan deviasi hasil pengukuran pyrometer yang diperlihatkan pada Gambar 10 dan Tabel 7 menunjukkan terdapat 3 data dari 21 data $(14,29 \%)$ berada di luar toleransi yang telah ditetapkan, yaitu: $\pm 30^{\circ} \mathrm{C}$. Garis merah pada Gambar 10 mewakili batas toleransi yang diperbolehkan. Penyimpangan data yang melebihi batas toleransi tersebut disebabkan oleh ketidakstabilan operator saat mengoperasikan pyrometer pada proses pengukuran. Hal ini menyebabkan beberapa bagian spot size pyrometer tidak mengenai area logam cair, sehingga nilai pengukuran menjadi lebih rendah. Nilai data tersebut tidak langsung turun menjadi $800^{\circ} \mathrm{C}$ (batas bawah pengukuran pyrometer) karena spot size dari pyrometer masih mengenai logam cair, namun pada bagian yang lebih dingin, yaitu: pengotor dan zat aditif yang ditambahkan saat proses pengecoran.

Tingkat bias dan variance pada data pengambilan sampel ketiga sebagaimana diperlihatkan pada Tabel 7 menunjukkan hasil yang cukup baik, yaitu: 0,5\% bias dan variance sebesar 375,5. Tingkat bias tersebut menunjukkan nilai yang lebih tinggi dibandingkan dengan data pada pengambilan sampel kedua, sedangkan variance menunjukkan hasil yang paling tinggi jika dibandingkan dengan data hasil pengambilan sampel pertama dan kedua.

Meskipun mayoritas data hasil pengukuran menunjukkan nilai yang masih dalam batas toleransi yang diizinkan, justifikasi pada sistem monitoring temperatur logam cair tersebut menunjukkan hasil yang cukup variatif. Tingkat bias pada data pengambilan sampel ketiga, yaitu $0,5 \%$ bias menunjukkan adanya peningkatan performa pada sistem monitoring temperatur. Hal itu menunjukkan bahwa akurasi pengukuran temperatur pada sistem monitoring temperatur sudah cukup mumpuni. Sedangkan, nilai variance sebesar 375,5 pada data pengambilan sampel ketiga menunjukkan bahwa tingkat presisi sistem monitoring temperatur masih cukup rendah. Tingkat variance yang tinggi ini berkaitan dengan faktor ketidakstabilan operator pada saat mengoperasikan pyrometer pada proses pengukuran, sehingga menyebabkan deviasi pada data hasil pengukuran temperatur yang melebihi bata toleransi yang diizinkan.

\section{Kesimpulan}

Sistem monitoring temperatur logam cair menggunakan pyrometer menunjukkan tingkat akurasi 99,5\% dan tingkat bias mencapai 0,5\%. Hasil yang berbeda ditunjukkan pada tingkat presisi sistem monitoring temperatur logam cair yang diindikasikan dengan tingkat variance yang tinggi. Tingkat variance pada data pengukuran temperatur mencapai 375,3 . Nilai yang tinggi ini disebabkan oleh ketidakstabilan operator saat mengoperasikan pyrometer. Hal ini merupakan faktor kesalahan random yang sulit untuk dikendalikan karena keterbatasan sistem yang sudah dibangun. Tingkat presisi pengukuran temperatur logam cair pada sistem monitoring menggunakan pyrometer dapat ditingkatkan dengan mengembangkan metode pengukuran secara otomatis untuk mengurangi faktor kesalahan pengoperasian pyrometer oleh operator.

\section{Ucapan Terima Kasih}

Terima kasih kami sampaikan kepada Moch. Iqbal Zaelana Muttahar, Sony Harbintoro, Alfa Anggawasita, Dimas, dan Muhammad Nauval Fauzi yang telah membantu dalam pengembangan sistem monitoring pyrometer berbasis IoT.

\section{Daftar Pustaka}

Boughton, P. (2013). The proven advantages of non- 


\section{TEKNIK, 42 (3), 2021, 308}

contact temperature measurement. Diakses pada Maret 10, 2020, dari

https://www.engineerlive.com/content/provenadvantages-non-contact-temperature-measurement

Domingos, P. (2012). A Few Useful Things to Know About Machine Learning. Communications of the ACM, 55(10), 9-48. https://doi.org/10.1007/978-3642-35289-8-3

Eryantono, A. E., Fauzi, M. N., \& Fathurrohman, M. (2020). Sistem Monitoring Temperatur Tuang Logam dan Penggunaan Energi Berbasis IoT di MIDC ( Metal Pouring Temperature and Energy Usage Monitoring System with IoT in MIDC). 9(2), 123-131.

eWon. (2020). eWON - Industrial VPN Routers: Remote Access \& Data Services. Diakses pada Maret 23, 2020, dari https://ewon.biz/products/ewon-flexy

Jack, K. E., Etu, I., \& Ukanide, V. N. (2016). The design of a signal conditioning and acquisition elements of a chopped broadband radiation pyrometer. Lecture Notes in Engineering and Computer Science, 2225(04), 338-344. https://doi.org/10.15623/ijret.2015.0404082

Kassie, A. A. (2013). Minimization of Casting Defects. IOSR Journal of Engineering, 03(05), 31-38. https://doi.org/10.9790/3021-03513138

Khandelwal, R. (2018). Bias and Variance in Machine Learning - Data Driven Investor - Medium. Diakses pada Mei 11, 2020, dari https://medium.com/datadriveninvestor/bias-andvariance-in-machine-learning-51fdd38d1f86

Mudjahidin, M., \& Putra, N. D. P. (2012). Rancang Bangun Sistem Informasi Monitoring Perkembangan Proyek Berbasis Web Studi Kasus di Dinas Bina Marga dan Pemantusan. Jurnal Teknik Industri, 11(1), 75. https://doi.org/10.22219/JTIUMM.Vol11.No1.7583

Müller, B., \& Renz, U. (2001). Development of a fast fiber-optic two-color pyrometer for the temperature measurement of surfaces with varying emissivities. Review of Scientific Instruments, $72(8)$ 3366-3374. https://doi.org/10.1063/1.1384448

Patel, K. K., \& Patel, S. (2016). IOT Based Data Logger for Monitoring and Controlling Equipment Working Status and Environmental Conditions. International Journal of Innovative Research in Computer and Communication Engineering, 4(4),
5103-5112.

https://doi.org/10.15680/IJIRCCE.2016.0404125

Prawastiyo, C. A., \& Hermawan, I. (2020). Pengembangan Front-End Website Perpustakaan Politeknik Negeri Jakarta Menggunakan Metode User Centered Design. Information Science and Library, 1(2), 1-11.

Rani, M. T., \& Sivakumar, R. (2021). Iot-based energy analytic platform for foundry units. Advances in Intelligent Systems and Computing, 1163, 701711. https://doi.org/10.1007/978-981-15-50294_58

Resende, C., Monteiro, M., Oliveira, J., Moreira, W., Cavaleiro, A., Silva, R., \& Carvalho, R. (2018). WGW4IIoT: Wireless Gateway for Industrial IoT. 2018 IEEE Symposium on Computers and Communications (ISCC), 2018-June, 0110801113. https://doi.org/10.1109/ISCC.2018.8538656

Rompis, A. C., \& Aji, R. F. (2018). Perbandingan Performa Kinerja Node.js, PHP, dan Python dalam Aplikasi REST. CogITo Smart Journal, 4(1), 171. https://doi.org/10.31154/cogito.v4i1.92.171-187

Sanjith, S., Balaji, N., Anand, L. D. V., Anne, W. R., Shanmugapriya, P., \& Rani, S. S. (2021). IoT enabled temperature sensing system of molten metal in welding. Materials Today: Proceedings, $45(2)$, 2514-2517. https://doi.org/10.1016/j.matpr.2020.11.124

Shah, H., \& Soomro, T. R. (2017). Node. Js Challenges in Implementation. Global Journals of Computer Science and Technology: E Network, Web \& Security, 17(2), 73-83.

Tapetado, A., Diaz-Alvarez, J., Miguelez, M. H., \& Vazquez, C. (2016). Two-color pyrometer for process temperature measurement during machining. Journal of Lightwave Technology, 34(4), 1380-1386. https://doi.org/10.1109/JLT.2015.2513158

Usamentiaga, R., Molleda, J., Garcia, D. F., Granda, J. C., \& Rendueles, J. L. (2012). Temperature measurement of molten pig iron with slag characterization and detection using infrared computer vision. IEEE Transactions on Instrumentation and Measurement, 61(5), 11491159. https://doi.org/10.1109/TIM.2011.2178675

Weyrich, M., \& Ebert, C. (2016). Reference architectures for the internet of things. IEEE Software, 33(1), 112-116. https://doi.org/10.1109/MS.2016.20 